\title{
Total resection of a giant retroperitoneal and mediastinal ganglioneuroma-case report and systematic review of the literature
}

Patrick Kirchweger ${ }^{1,2^{*}}$ D, Helwig Valentin Wundsam¹, Ines Fischer ${ }^{1}$, Christiane Sophie Rösch ${ }^{3}$, Gernot Böhm Oleksiy Tsybrovskyy ${ }^{5}$, Vedat Alibegovic ${ }^{5}$ and Reinhold Függer ${ }^{1,2,3}$

\begin{abstract}
Background: Ganglioneuromas (GNs) are extremely rare, slowly growing, benign tumors that can arise from Schwann cells, ganglion cells, and neuronal or fibrous tissues. Due to their origin from the sympathetic neural crest, they show neuroendocrine potential; however, most are reported to be hormonally inactive. Nevertheless, complete surgical removal is recommended for symptom control or for the prevention of potential malignant degeneration.

Case Report: A 30-year-old female was referred to our oncologic center due to a giant retroperitoneal and mediastinal mass detected in computed tomography (CT) scans. The initial symptoms were transient nausea, diarrhea, and crampy abdominal pain. There was a positive family history including 5 first- and second-degree relatives. Presurgical biopsy revealed a benign ganglioneuroma. Total resection (TR) of a $35 \times 25 \times 25 \mathrm{~cm}, 2550-\mathrm{g}$ tumor was obtained successfully via laparotomy combined with thoracotomy and partial incision of the diaphragm. Histopathological analysis confirmed the diagnosis. Surgically challenging aspects were the bilateral tumor invasion from the retroperitoneum into the mediastinum through the aortic hiatus with the need of a bilateral 2-cavity procedure, as well as the tumor-related displacement of the abdominal aorta, the mesenteric vessels, and the inferior vena cava. Due to their anatomic course through the tumor mass, the lumbar aortic vessels needed to be partially resected. Postoperative functioning was excellent without any sign of neurologic deficit.

Conclusion: Here, we present the largest case of a TR of a GN with retroperitoneal and mediastinal expansion. On review of the literature, this is the largest reported GN resected and was performed safely. Additionally, we present the first systematic literature review for large $G N(>10 \mathrm{~cm})$ as well as for resected tumors growing from the abdominal cavity into the thoracic cavity.
\end{abstract}

Keywords: Case report, Largest, Thoracoabdominal, Ganglioneuroma, Systematic review

\footnotetext{
*Correspondence: patrick.kirchweger@ordensklinikum.at

'Department of General and Visceral Surgery, Ordensklinikum Linz -

Barmherzige Schwestern, Linz, Austria

${ }^{2}$ Medical Faculty, Johannes Kepler University Linz, Linz, Austria

Full list of author information is available at the end of the article
}

(C) The Author(s). 2020 Open Access This article is licensed under a Creative Commons Attribution 4.0 International License, which permits use, sharing, adaptation, distribution and reproduction in any medium or format, as long as you give appropriate credit to the original author(s) and the source, provide a link to the Creative Commons licence, and indicate if changes were made. The images or other third party material in this article are included in the article's Creative Commons licence, unless indicated otherwise in a credit line to the material. If material is not included in the article's Creative Commons licence and your intended use is not permitted by statutory regulation or exceeds the permitted use, you will need to obtain permission directly from the copyright holder. To view a copy of this licence, visit http://creativecommons.org/licenses/by/4.0/ The Creative Commons Public Domain Dedication waiver (http://creativecommons.org/publicdomain/zero/1.0/) applies to the data made available in this article, unless otherwise stated in a credit line to the data. 


\section{Background}

Ganglioneuromas (GNs) are extremely rare $(1 / 1,000$, 000 ), slowly growing, benign tumors that can arise from Schwann cells, ganglion cells, and neuronal $(0.1-0.5 \%$ of neurogenic tumors) or fibrous tissues [1-3]. First described by Loretz in 1870, they are most commonly seen in pediatric populations, with $60 \%$ of total diagnoses occurring prior to the age of 20 . The median age at the time of the diagnosis is reported to be approximately 7 years [4]. Ganglioneuromas, in general, occur more frequently in females than in males with a ratio of about 3 : 2 [5]. As these tumors are generally diagnosed due to compressive symptoms and consequently resected in children, there is usually a natural limit to tumor size given by the available space within the body cavity. The biggest resected GN assessable through literature research up to now showed a maximum diameter of approximately $23 \mathrm{~cm} \mathrm{[6]} \mathrm{in} \mathrm{a} \mathrm{42-year-old} \mathrm{patient} \mathrm{located}$ solely thoracically [6]. Located most commonly in the posterior mediastinum (41.5\%) or retroperitoneally (37.5\%), ganglioneuromas can be found in the adrenal glands $(21 \%)$, in the neck (8\%), retropharyngeally, or more rarely in the sella turcica [7-10]. Computed tomography (CT) or magnetic resonance imaging (MRI) represents the gold standard for diagnosis and estimation of tumor extent. Microscopically, the absence of mitotic figures, intermediate cells, neuroblasts, or necrosis distinguishes a GN from their main differential diagnoses, ganglioneuroblastoma and paraganglioma, which are considered functioning tumors [11, 12]. Ganglioneuromas show neuroendocrine potential which is attributable to their origin from the sympathetic neural crest, but the majority of them are reported to be hormonally inactive [13]. However, GNs have shown to have a secretory function in up to $39 \%$ of cases in some studies [2]. Elevated levels of metanephrine, catecholamine, vasoactive intestinal peptide (VIP), dopamine, cortisol, homovanillic acid (HVA), or vanillylmandelic acid (VMA) can be potentially detected in the blood or urine of patients, especially if the adrenal gland is involved. Currently, metanephrine detection in the plasma of patients is regarded as the gold standard for the detection of catecholamine-releasing tumors. These tumors are much more likely to cause symptoms such as hypertensive crisis, diarrhea, virilization due to hormonal imbalance, and depressive disorders [13-17]. Some studies indicate an association between a diagnosed ganglioneuroma and genetic diseases like multiple endocrine neoplasia type 2 or neurofibromatosis type 1 or 2 [3]. Malignant degeneration of a ganglioneuroma occurs even more rarely, with the highest prevalence occurring when tumors are penetrating into the spinal canal via the neural foramen, with transformation into neuroblastoma [18-21]. Thus, complete surgical removal is recommended for symptom control or prevention of potential malignant degeneration [22]. Furthermore, subsequent long-term follow-up including imaging controls is mandatory to prevent potential relapse, especially when only partial tumor removal was achieved. There is no need for neoadjuvant or adjuvant antineoplastic treatment [1]. Additionally, prognosis after total tumor resection is deemed to be excellent, although surgical morbidity has to be taken into account especially when dealing with large GN [2].

We report the largest resected ganglioneuroma expanding from the retroperitoneum to the thoracic cavity. Currently, there is no systematic review of large resected ganglioneuroma or thoracoretroperitoneal tumors. We conducted a literature review adhering to the PRISMA guidelines to address this issue and to place our findings in the context of the current literature.

\section{Methods}

First, we present our patient in terms of preoperative imaging, surgical therapy, and postoperative outcome. The case report was conducted adhering to the CARE guidelines [23]. The required checklist is provided in the supplementary material (Supplementary file 1).

Second, in January 2020, a systematic literature research for big GN $(>10 \mathrm{~cm})$ was conducted using the terms $<$ large $>$ OR $<$ largest $>$ OR $<$ big $>$ OR $<$ biggest $>$ OR $<$ giant $>$ OR $<$ huge $>$ OR $<$ massive $>$ OR $<$ retroperitoneal $>$ OR $<$ mediastinal $>$ AND $<$ resected $>$ OR $<$ resection $>$ OR $<$ surgery $>$ AND <ganglioneuroma $>$ on PubMed and MEDLINE research to isolate all cases of the largest resected GN in all locations as well as GN with retroperitoneal and mediastinal expansion.

Third, a systematic literature research was conducted for the identification of all resected tumors with expansion from the retroperitoneum to the mediastinum by using the MeSH terms <tumor $>$, <mediastinum $>$, < retroperitoneum $>$, and $<$ resection $>$ as well as $<$ thoracoabdominal $>$, <tumor $>$, and $<$ resection $>$ on PubMed and MEDLINE in February 2020. The papers were reviewed, and reports of gastric or esophageal cancers as well as spinal cord surgery were excluded.

No further specific eligibility criteria were used to address all reported cases and possibly existing case series, except the ones mentioned above and visualized in Fig. 4.

Systematic reviews were conducted in accordance with the search adhering to the PICOS strategy, and reporting was done subject to the regulations of the Preferred Reporting Items for Systematic Reviews and Meta-Analyses (PRIS MA) guidelines [24]. The complete checklist is provided in the supplementary material (Supplementary file 2).

\section{Case report}

A 30-year-old female (Table 1) was referred to our surgical department because of a giant retroperitoneal and 
Table 1 Table of patient characteristics

\begin{tabular}{ll}
\hline Age & $\mathbf{3 0}$ \\
\hline Sex & Female \\
BMl & 31.60 \\
Height $(\mathrm{m})$ & 1.64 \\
Weight $(\mathrm{kg})$ & 85 \\
CCl & 0 \\
ECOG & 0 \\
Smoking & None \\
Drugs & None
\end{tabular}

BMI Body mass index, CCI Charlson Comorbidity Index, ECOG Eastern Cooperative Oncology Group Performance Index

mediastinal mass detected in an ultrasound performed outside of our facility as well as in CT imaging. Her medical history prior to admission was unremarkable, including no long-term medications and no reported pre-existing medical conditions. The initial symptoms were transient nausea, diarrhea, and crampy, left lower quadrant abdominal pain persisting for 2 weeks with a rough palpable mass in physical examination. Family history was positive for cancer, including 5 first- and second-degree relatives (Fig. 1).

Initial laboratory examination revealed inflammatory and tumor markers within normal limits. Further CT imaging demonstrated the involvement of the abdominal and thoracic cavities with tumor mass expansion from the retroperitoneum through the aortic hiatus to the posterior mediastinum with a concordant displacement of the major central vessels (Fig. 2).

Presurgical CT-guided biopsy verified a benign ganglioneuroma. Thus, complete surgical resection was recommended in a symptomatic patient. Total resection (TR) of a $35 \times 25 \times 25 \mathrm{~cm}, 2550$-g tumor via laparotomy and partial diaphragm incision were performed successfully.

Postoperative histological analysis confirmed the diagnosis (Fig. 3). Surgically challenging aspects resulted from the bilateral tumor invasion of the retroperitoneum and the mediastinum through the aortic hiatus, as well as the tumor-related displacement of the abdominal aorta, the mesenteric vessels, and the inferior vena cava. Additionally, the tumor grew between the inferior vena cava and aorta, with the need of comprehensive separation up to the aortic hiatus, where the tumor entered the posterior mediastinum on both sides. Despite the necessity of partial resection of several lumbar aortic vessels due to perivascular tumor growth, postoperative functioning of the patient showed no signs of neurologic impairment. Regular wound drainages (two located intraabdominally and one in the thoracic space) could be removed at day 3 with an output of less than $100 \mathrm{ml}$. Unfortunately, the patient developed a chylous ascites which required continuous fluid drainage via a Pleur $\mathrm{X}^{\mathrm{mx}}$ system, which was placed retroperitoneally on day 9 postoperatively. This was not completely unexpected due to the vast extent of lymph vessel resection. Supportive medium-chain triglycerides (MCT) diet improved the drain output, such that the Pleur $\mathrm{X}^{\mathrm{Tn}}$ drain could be removed at day 27 postoperatively, and the patient was discharged on day 32 postoperatively. Afterwards, no further medication or therapy was needed. At the 6-month follow-up, the patient reported no negative impacts and no restrictions on her activities of daily living in comparison with her preoperative status.

\section{Systematic literature review}

A total of 64 papers fulfilled the MESH terms for big resected ganglioneuroma from June 1957 to January 2020. Subsequently, 13 of those reported cases were thoracoabdominal tumors and 10 were $\mathrm{GN}$ over $10 \mathrm{~cm}$ (Table 2, Fig. 4).

None of these large $(>10 \mathrm{~cm}$ ) resected GN showed expansion to both body cavities. Therefore, the natural cap of tumor mass growth was assumed to be limited by the provided space before any symptom onset was noticed by the patient. The largest GN currently reported was $23 \mathrm{~cm}$ in diameter [6]. Thus, our case currently ranks as the largest resected ganglioneuroma. Regarding other aspects of the literature, the gender balance was almost even in the reported cases with 7:6 in favor of women. Tumors were located as follows: 7 retroperitoneal, 4 thoracic, and one retropharyngeal as well as one presacral case. A laparoscopic approach was only conducted once concordant with an adrenalectomy, whereas open surgical procedures were performed in the remaining 12 cases. Total resection, on the other hand, was performed in 10 out of 13 cases. In the remaining three cases, one was removed piecemeal in one procedure, whereas a second surgical approach was necessary in the remaining two cases [5, 32]. Twelve out of 13 papers reported the absence of surgical complications or postoperative unexpected events. Unexpected postoperative pain and hypertensive disorders were observed in one patient. Moreover, no relapse was seen at a mean follow-up period of 19.44 ( $\min .7$, max. 48, standard deviation 13.88) months.

A second literature review with extension to all resected tumors with thoracoabdominal expansion was conducted to match our case. A total of 96 papers fulfilling the terms <tumor $>$, <mediastinum $>$, <retroperitoneum $>$, and $<$ resection $>$ as well as 214 papers fulfilling the MESH terms <thoracoabdominal>, <tumor >, and < resection $>$ were evaluated. All tumors that are naturally located thoracoabdominal (e.g., esophagus, stomach) as well as spinal cord (e.g., dumbbell) tumors were neglected in this review. The review resulted in a total of 10 papers and 11 cases of tumors with mediastinal and retroperitoneal expansion that are listed in Table 3. 


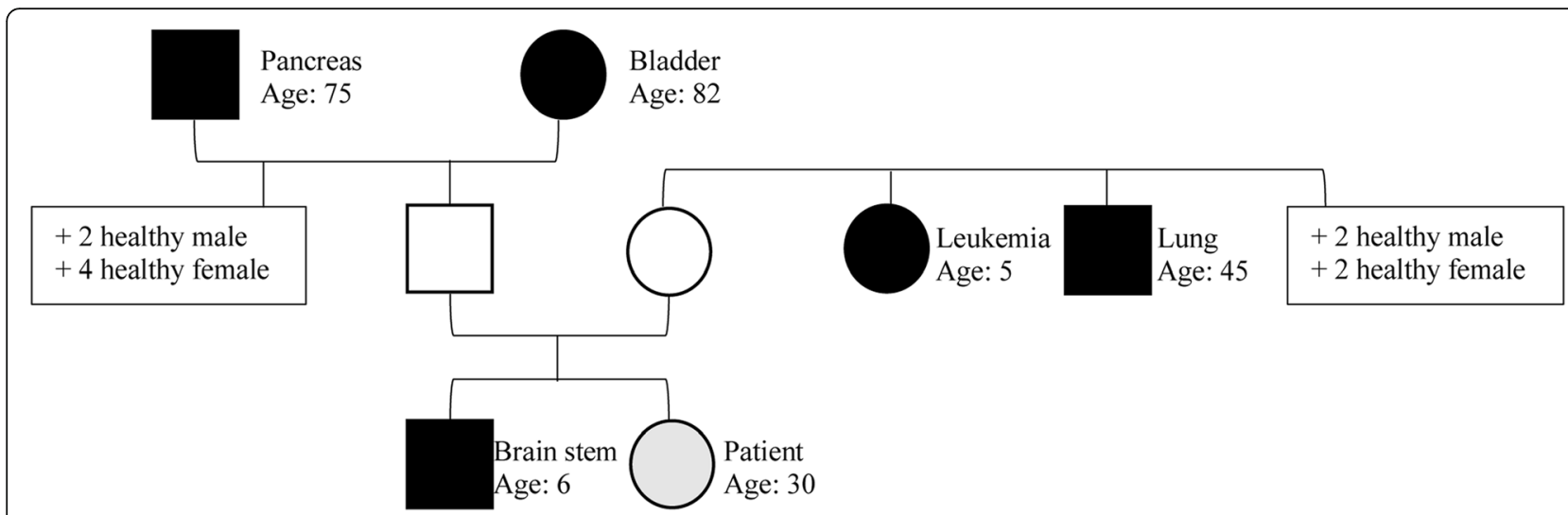

Fig. 1 Pedigree with aspect to malignant diseases. Relatives who developed tumor diseases are marked black. Circle, female; square, male

According to our research, the largest resected tumor ever appears to be a liposarcoma in a 39-yearold man presenting with chest pain in 2011 with a size of $40 \mathrm{~cm} \mathrm{[34].} \mathrm{Open} \mathrm{total} \mathrm{resection} \mathrm{was} \mathrm{per-}$ formed safely without peri- or postoperative complications. Thus, our case currently ranks as the second largest thoracoabdominal tumor. Gender relation within this research was 6:2 in favor of men, whereas the mean age was 30 years, but again appeared very heterogeneously distributed (min. 1, max. 74, standard deviation 25.12). Laparoscopic approach was only performed once in a case of a small ganglioneuroma (8 $\mathrm{cm}$ ), with the remaining procedures being performed open. Nevertheless, total resection was feasible in all reported cases accessible.
Surgical complications were only reported in one case report of a schwannoma mainly located at the posterior mediastinum. Furthermore, not a single case of relapse was seen at a mean follow-up period of 24.8 (min. 2, max. 84, standard deviation 33.43) months.

\section{Discussion}

This study presents novel findings in three aspects. First, we report the resection of the largest ganglioneuroma to date $(23$ vs. $35 \mathrm{~cm})$. GN growth is usually limited by the provided space in the body cavity and the resulting symptoms. Tumors exceeding $10 \mathrm{~cm}$ in diameter are very rare in a disease that occurs mostly in children. Of particular interest is the expansion of the tumor through the aortic hiatus into the thoracic cavity without exerting
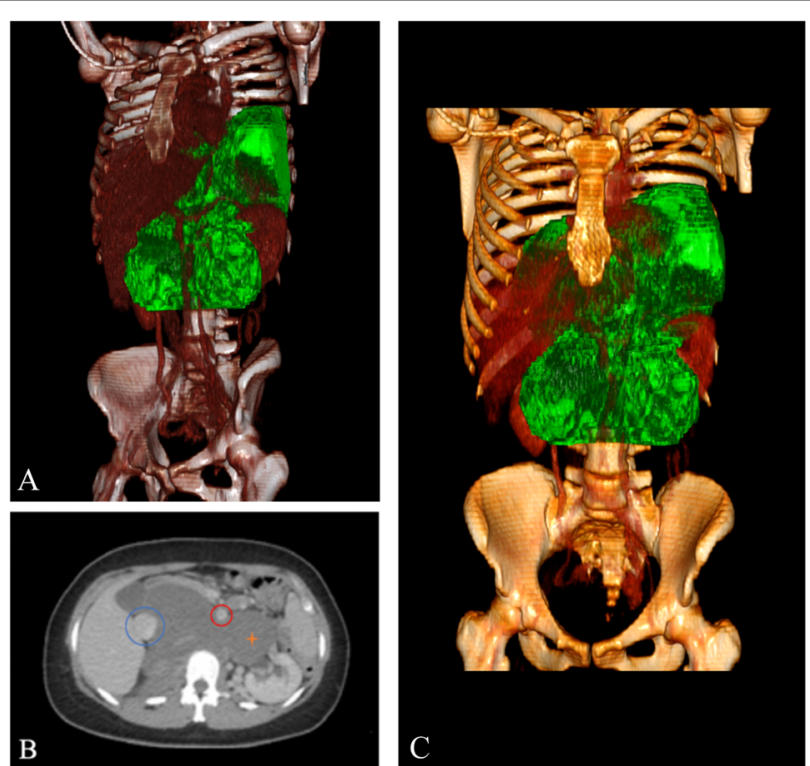

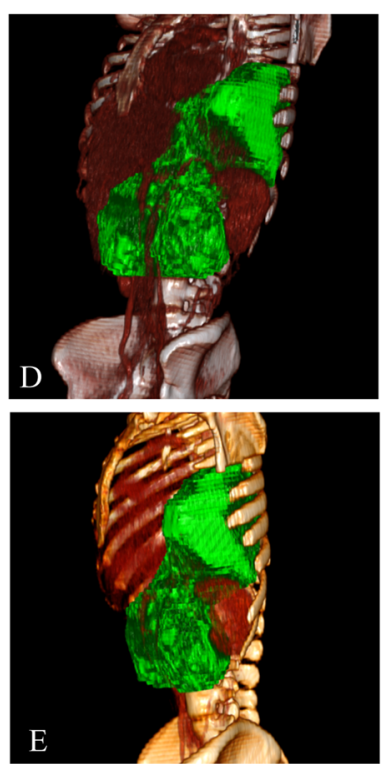

Fig. 2 CT images and 3D reconstruction. The GN (green) extends from the retroperitoneal space through the aortic hiatus into the posterior mediastinum and surrounds (a, c-e) and displaces (b) Inferior vena cava $\mathbf{O}$, aorta $\mathbf{O}$, tumor $\mathfrak{t}$ 



Fig. 3 Macroscopic and microscopic findings. a Macroscopic specimen of the in toto resected GN. b, c H\&E-stained histopathological images of the central tumor portion with ganglion cells and stromal tissue as well as myxofibrotic and fat tissue in the transition zone. H\&E, hematoxylin and eosin staining

pressure to the surrounding organs. This is an uncommon finding in GN.

Literature research resulted in 13 cases of resected GN of more than $10 \mathrm{~cm}$, with the largest tumors in adults of which the majority were located in the abdomen.

Second, we report the second largest tumor resected with expansion into both the abdominal and thoracic cavities with the limitation of excluding tumors with per se thoracoabdominal growth like dumbbell tumor of the thoracolumbar spine or esophagus or gastric carcinoma. The literature review resulted in only 2 cases of thoracoabdominal GN. The first was reported in a 3.5year-old girl in 2003, where surgery was skipped due to the highly challenging anatomy and the parents' will [44]. The second case was reported quite recently in November 2019 in a 10-year-old girl with a paraspinal GN extending from T9-L1, and thus fulfilling the definition of a thoracoabdominal mass. It was also reported to be the first resection of a thoracoabdominal ganglioneuroma [45]. This case showed no involvement of the major vessels, but the described tumor was located close to the right renal artery. The mass showed an expansion of

Table 2 Systematic literature review for large resected GN (> $10 \mathrm{~cm}$ max. diameter)

\begin{tabular}{|c|c|c|c|c|c|c|c|}
\hline Year $^{a}$ & Age & Sex & Localization & DM & Procedure $\left({ }^{c}\right)$ & Complications & Relapse (FU) \\
\hline 2018 [6] & 42 & q & Thoracic & 23 & Open TR & None & n.a. \\
\hline $2006[25]^{b}$ & 35 & 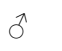 & Retroperitoneal & 22 & Open TR & None & No (48) \\
\hline 2017 [3] & 21 & $\hat{\sigma}$ & Retroperitoneal & 21.5 & Open TR & None & No (12) \\
\hline 2013 [26] & 18 & $\hat{0}$ & Retropharyngeal & 19 & Open TR & None & No (7) \\
\hline 2011 [27] & 53 & $\hat{\sigma}$ & Retroperitoneal & 19 & Open TR & None & No (24) \\
\hline 2019 [1] & 4 & $\hat{0}$ & Retroperitoneal & 17.3 & Open PR & None & n.a. \\
\hline 2017 [28] & 5 & $\hat{\sigma}$ & Mediastinal & 16 & Open TR & None & n.a. \\
\hline 2016 [29] & 42 & 우 & Retroperitoneal & 14.5 & Open TR & None & No (12) \\
\hline 2007 [30] & 23 & 우 & Retroperitoneal & 13 & Lap. TR & None & No (12) \\
\hline 2013 [31] & 12 & q & Presacral & 12 & Open TR & None & No (12) \\
\hline 2017 [32] & 12 & q & Thoracic & 12 & Open PR (2) & None & No (12) \\
\hline 2014 [33] & 66 & q & Thoracic & 12 & n.a. & Pain, hypertension & No (36) \\
\hline 2016 [5] & 12 & q & Retroperitoneal & 13 & Open PR (8) & None & n.a. \\
\hline
\end{tabular}

FU Follow-up in months, $T R$ Total resection, $P R$ Partial resection, DM Maximum diameter (in $\mathrm{cm}$ )

${ }^{\text {a }}$ Citations in brackets

${ }^{\text {b} A r t i c l e ~ i n ~ J a p a n e s e ~}$

${ }^{c}$ Completion in weeks 


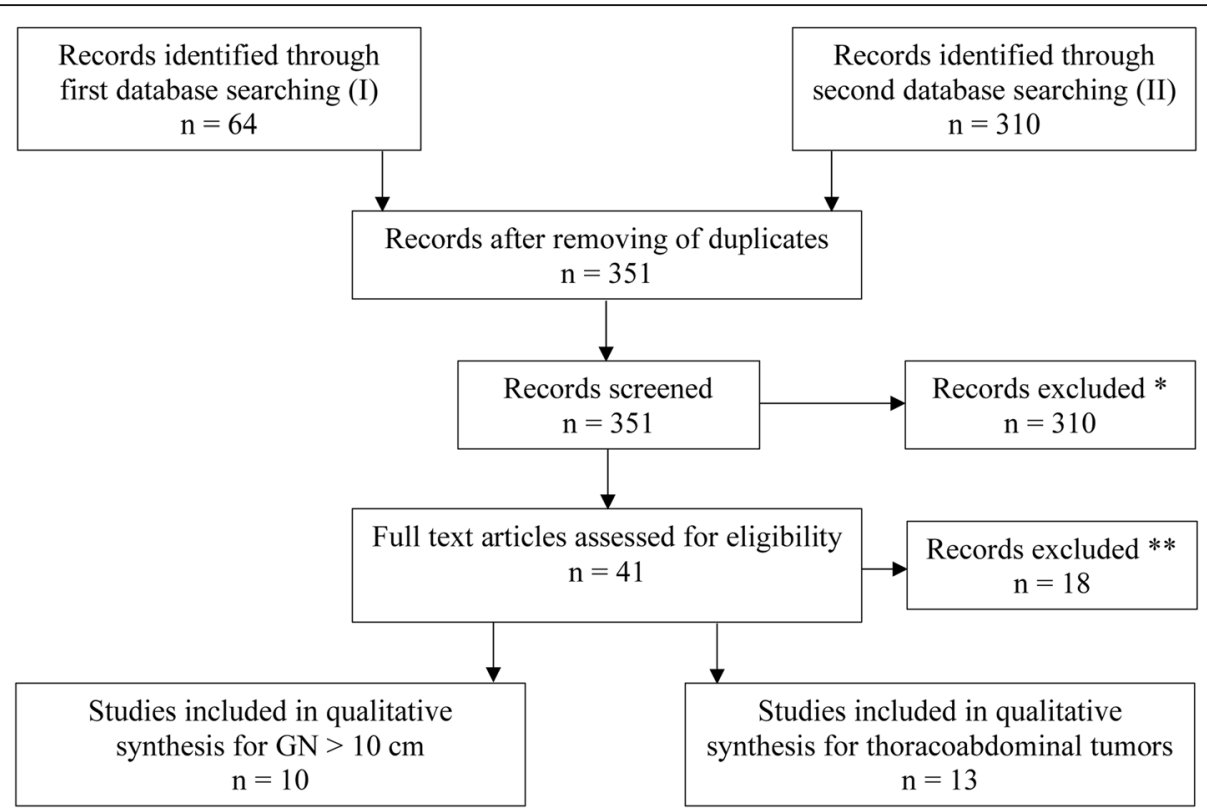

Fig. 4 PRISMA consort diagram of how the literature was screened. *Trivial cases of gastric or esophageal cancers as well as spinal cord surgery, which are naturally located thoracoabdominal (e.g., T1-L2 in spinal dumbbell tumors), were excluded. **Mostly thoracoabdominal approach for solely intraabdominally located tumors

about $8 \mathrm{~cm}$, and TR was obtained solely through the laparoscopic abdominal approach with a small incision and afterwards suture of the diaphragm. Therefore, thoracic involvement was minimal. The current largest thoracoabdominal tumor, a 40-cm liposarcoma, was resected in 2011 via laparotomy and thoracotomy [34]. The undiscussed cases were much smaller in size (Table 3). Additionally, most of these rare cases are presented in case reports without systematic structures such as CARE guidelines and therefore lack quality criteria for a comprehensive comparison. At the time of writing, there does not exist a single case series of big resected ganglioneuromas or tumors with characteristics discussed in this report. Thus, lacking systematic procedure evaluation, the surgical approach depends on the surgeon's choice as evidence is limited.

Third, removal of big thoracoabdominal tumors may be challenging. A laparoscopic approach may be considered but is restricted to selected smaller tumors. Moreover, the required incision for the final in toto tumor removal from the abdominal cavity would render prior minimally invasive efforts futile. Preoperative diagnostic imaging and functional tests are mandatory to evaluate, for example, tumor vessel invasion like in our case [1], spinal cord invasion [18-21,32], or potential hormoneproducing tumors especially in retroperitoneal/adrenal

Table 3 Systematic literature review for resected thoracoabdominal growing tumors

\begin{tabular}{|c|c|c|c|c|c|c|c|c|c|}
\hline Year $^{a}$ & $n$ & Entity & Age (years) & Sex & Symptoms & DM & Procedure & Complications & Relapse (FU) \\
\hline 2011 [34] & 1 & Liposarcoma & 39 & $\hat{o}$ & Chest pain & 40 & Open TR & None & None (14) \\
\hline 2019 [35] & 1 & Schwannoma & 58 & 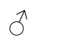 & Cough & 20.2 & Open TR & Partial lung expansion & None (n.a.) \\
\hline 2019 [36] & 1 & GN & 10 & q & Cough & 8 & Lap. TR & None & None (12) \\
\hline 2019 [37] & 1 & Neuroblastoma & 24 & $\hat{\sigma}$ & Chest pain & 7 & Open TR & None & None (12) \\
\hline 2019 [38] & 1 & Sarcoma & 74 & q & None & 3 & Open TR & None & None (2) \\
\hline 2014 [39] & 1 & GNB & 17 & $\hat{\sigma}$ & n.a. & n.a. & Open TR & n.a. & n.a. \\
\hline 2010 [40] & 1 & Teratoma & 1 & 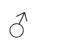 & n.a. & n.a. & Open TR & None & None (84) \\
\hline 2009 [41] & 1 & Osteochondroma & 17 & $\hat{\sigma}$ & n.a. & n.a. & Open TR & n.a. & n.a. \\
\hline 2004 [42] & 1 & n.a. & n.a. & n.a. & n.a. & n.a. & n.a. & n.a. & n.a. \\
\hline 1993 [43] & 2 & Neuroblastoma & n.a. & n.a. & n.a. & n.a. ${ }^{b}$ & n.a. & n.a. & n.a. \\
\hline
\end{tabular}

$n$ case number, $T R$ total resection, $P R$ partial resection, $D M$ maximum diameter (in $\mathrm{cm}$ ), $F U$ follow-up in months ${ }^{\mathrm{a}}$ Citation in brackets

${ }^{\mathrm{b}}$ Exact max. size unknown, but $<10 \mathrm{~cm}$ according to the provided imaging 
cases [2, 13-17]. Approaches differ markedly depending on the center's expertise. This is not surprising as the literature merely consists of case reports. Only one out of 13 cases for resection of big GN and one out of 10 cases for thoracoabdominal tumors presented with peri- or postoperative complications, respectively. We assume that perioperative complications are underreported with respect to the extended resections necessary for tumor removal. In our case, a common complication of extended thoracoabdominal surgical procedures, a chyle leak, occurred. Avoidance of re-operation was achieved with a temporary continuous wound fluid drainage and supportive mediumchain triglycerides (MCT) diet.

In summary, early total resection for symptom control and prevention of potential malignant degeneration as well as regular imaging control during follow-up is recommended, although relapse is rare.

\section{Patient perspective}

"Thinking of the big scar remaining from laparotomy frightened me in a stigmatizing way. Additionally, recovery from surgery took some time and the need of prolongated wound fluid drainage made me feel desperate, but in the end, I could return to normal life without any restrictions."

\section{Limitations of the study}

Although we tried to limit potential reporting and systematic research bias by adhering to the PRISMA and CARE guidelines, we are aware of the possibility of inadvertently omitting papers not meeting our MeSH terms.

To our knowledge, there is no standard definition for large ganglioneuroma. The given cutoff (over $10 \mathrm{~cm}$ ) represents a subjective threshold we used to provide a complete overview of a manageable and easily understandable cohort (the biggest GN that had been resected in the past).

\section{Supplementary information}

Supplementary information accompanies this paper at https://doi.org/10. 1186/s12957-020-02016-1.

Additional file 1: Supplementary File 1. CARE checklist of information to include when writing a case report.

Additional file 2: Supplementary File 2. PRISMA checklist of information to include when writing a systematic review.

\section{Abbreviations}

GN: Ganglioneuroma; CT: Computed tomography; MRI: Magnetic resonance imaging; VIP: Vasoactive intestinal peptide; VMA: Vanillyl mandelic acid; TR: Total resection; PR: Partial resection; H\&E: Hematoxylin and eosin; T: Thoracic vertebra; L: Lumbal vertebra; GNB: Ganglioneuroblastoma; MCT: Medium-chain triglycerides

\section{Acknowledgements}

Acknowledgement to the Department of Pathology and the Department of Radiology of Ordensklinikum Linz Barmherzige Schwestern for providing the histopathological as well as radiological images.

\section{Authors' contributions}

PK reviewed the literature, collected the patient data, and drafted the manuscript. GB provided and adapted the radiologic images and revised the imaging part. OT and VA provided, adapted, and revised the histopathological part. HW, IF, CR, and RF revised the manuscript. RF carried out the operation, reported it, and provided the medical images. The final manuscript was read and approved by all authors.

\section{Funding}

None.

\section{Availability of data and materials}

The datasets used and/or analyzed during the current study are available from the corresponding author on reasonable request.

Ethics approval and consent to participate

The need for approval was waived by the ethics committee of Upper Austria.

Consent for publication

Informed consent for publication was attained from the patient.

\section{Competing interests}

The authors declare that they have no competing interests.

\section{Author details}

${ }^{1}$ Department of General and Visceral Surgery, Ordensklinikum Linz Barmherzige Schwestern, Linz, Austria. ${ }^{2}$ Medical Faculty, Johannes Kepler University Linz, Linz, Austria. ${ }^{3}$ Department of General, Visceral, Vascular, Thoracic and Transplantation Surgery, Ordensklinikum Linz - Elisabethinen, Linz, Austria. ${ }^{4}$ Department of Radiology, Ordensklinikum Linz - Barmherzige Schwestern, Linz, Austria. ${ }^{5}$ Department of Pathology - Vinzenz

Pathologieverbund, Ordensklinikum Linz, Linz, Austria.

Received: 10 April 2020 Accepted: 31 August 2020

Published online: 18 September 2020

\section{References}

1. Zheng X, Luo L, Han FG. Cause of postprandial vomiting - a giant retroperitoneal ganglioneuroma enclosing large blood vessels: a case report. World J Clin Cases. 2019;7(17):2617-22

2. Geoerger B, Hero B, Harms D, Grebe J, Scheidhauer K, Berthold F. Metabolic activity and clinical features of primary ganglioneuromas. Cancer. 2001; 91(10):1905-13.

3. Rahnemai-Azar AA, Griesemer AD, Velasco ML, Kato T. Ex vivo excision of retroperitoneal soft tissue tumors: a case report. Oncol Lett. 2017;14(4): 4863-5.

4. Scherer A, Niehues T, Engelbrecht V, Modder U. Imaging diagnosis of retroperitoneal ganglioneuroma in childhood. Pediatr Radiol. 2001;31(2): 106-10

5. Yang Y, Ren M, Yuan Z, Li K, Zhang Z, Zhang J, et al. Thoracolumbar paravertebral giant ganglioneuroma and scoliosis: a case report and literature review. World J Surg Oncol. 2016;14:65.

6. Lambdin JT, Lee KB, Trachiotis G, Picone C. Massive thoracic ganglioneuroma with significant mass effect on left hemithorax. BMJ Case Rep. 2018;2018.

7. Linos D, Tsirlis T, Kapralou A, Kiriakopoulos A, Tsakayannis D, Papaioannou D. Adrenal ganglioneuromas: incidentalomas with misleading clinical and imaging features. Surgery. 2011;149(1):99-105.

8. Yang Al, Ozsvath J, Shukla P, Fatterpekar GM. Retropharyngeal ganglioneuroma: a case report. J Neuroimaging. 2013;23(4):537-9.

9. Yang B, Yang C, Sun Y, Du J, Liu P, Jia G, et al. Mixed gangliocytomapituitary adenoma in the sellar region: a large-scale single-center experience. Acta Neurochir (Wien). 2018;160(10):1989-99.

10. Bridenstine M, Kerr JM, Lillehei KO, Kleinschmidt-DeMasters BK. Cushing's disease due to mixed pituitary adenoma-gangliocytoma of the posterior 
pituitary gland presenting with Aspergillus sp. sinus infection. Clin Neuropathol. 2013;32(5):377-83.

11. Lonergan GJ, Schwab CM, Suarez ES, Carlson CL. Neuroblastoma, ganglioneuroblastoma, and ganglioneuroma: radiologic-pathologic correlation. Radiographics. 2002;22(4):911-34.

12. Bove KE, McAdams AJ. Composite ganglioneuroblastoma. An assessment of the significance of histological maturation in neuroblastoma diagnosed beyond infancy. Arch Pathol Lab Med. 1981;105(6):325-30.

13. AlGhamdi MH, AlAyed A, AlShabyli NA, AlGhamdi NH, AlRasheed M. Concurrent adrenal and extra-adrenal ganglioneuromas: a case report. Am J Case Rep. 2019;20:1817-20.

14. Koch CA, Brouwers FM, Rosenblatt K, Burman KD, Davis MM, Vortmeyer AO, et al. Adrenal ganglioneuroma in a patient presenting with severe hypertension and diarrhea. Endocr Relat Cancer. 2003;10(1):99-107.

15. Diab DL, Faiman C, Siperstein AE, Zhou M, Zimmerman RS. Virilizing adrenal ganglioneuroma in a woman with subclinical Cushing syndrome. Endocr Pract. 2008;14(5):584-7.

16. Erem C, Kocak M, Cinel A, Erso HO, Reis A. Dopamine-secreting adrenal ganglioneuroma presenting with paroxysmal hypertension attacks. Saudi Med J. 2008;29(1):122-5.

17. Chai L, Ciullo S, Prasad R. Case report of severe psychiatric sequelae in a 16year-old female following resection of a purely dopamine-secreting ganglioneuroma. Int J Surg Case Rep. 2019;61:263-6.

18. Hayashi Y, Iwato M, Hasegawa M, Tachibana O, von Deimling A, Yamashita J. Malignant transformation of a gangliocytoma/ganglioglioma into a glioblastoma multiforme: a molecular genetic analysis. Case report. Neurosurg. 2001;95(1):138-42.

19. Kulkarni AV, Bilbao JM, Cusimano MD, Muller PJ. Malignant transformation of ganglioneuroma into spinal neuroblastoma in an adult. Case report. J Neurosurg. 1998:88(2):324-7.

20. Shimada H, Ambros IM, Dehner LP, Hata J, Joshi W, Roald B. Terminology and morphologic criteria of neuroblastic tumors: recommendations by the International Neuroblastoma Pathology Committee. Cancer. 1999;86(2):349-63.

21. Ambros IM, Hata J, Joshi W, Roald B, Dehner LP, Tuchler H, et al. Morphologic features of neuroblastoma (Schwannian stroma-poor tumors) in clinically favorable and unfavorable groups. Cancer. 2002;94(5):1574-83.

22. de Chadarevian JP, MaePascasio J, Halligan GE, Katz DA, Locono JA, Kimmel S, et al. Malignant peripheral nerve sheath tumor arising from an adrenal ganglioneuroma in a 6-year-old boy. Pediatr Dev Pathol. 2004;7(3):277-84.

23. Gagnier JJ, et al. The CARE guidelines: consensus-based clinical case report guideline development. J Clin Epidemiol. 2014. https://doi.org/10.1016/j. jclinepi.2013.08.003.

24. Moher D, Liberati A, Tetzlaff J, Altman DG. Preferred Reporting Items for Systematic Reviews and Meta-Analyses: the PRISMA statement. J Clin Epidemiol. 2009. https://doi.org/10.1016/j.jclinepi.2009.06.005.

25. Komai Y, et al. A case of cystic ganglioneuroma of adrenal gland presenting as a huge retroperitoneal mass. Acta Urol Jpn. 2006.

26. Urata S, Yoshida M, Ebihara Y, Asakage T. Surgical management of a giant cervical ganglioneuroma. Auris Nasus Larynx. 2013;40(6):577-80. https://doi. org/10.1016/j.anl.2013.01.005.

27. Lai MC, Wang CC, Lin WC, Liu KL, Huang KH. Huge adrenal ganglioneuroma. Urology. 2011. https://doi.org/10.1016/j.urology.2010.05.006

28. Khan HAR, Khan FW, Fatimi SH. Giant ganglioneuroma in a 5-year child. J Coll Physicians Surg Pak. 2017.

29. Proposito D, et al. Tips to facilitate a preoperative diagnosis of adrenal ganglioneuroma. Report of a challenging experience and review of the literature. Ann Ital Chir. 2016;87:S2239253X16024208. Published 2016 Feb 10.

30. Zografos GN, Kothonidis K, Ageli C, et al. Laparoscopic resection of large adrenal ganglioneuroma. JSLS. 2007;11(4):487-92.

31. Lynch NP, Neary PM, Fitzgibbon JF, Andrews EJ. Successful management of presacral ganglioneuroma: a case report and a review of the literature. Int J Surg Case Rep. 2013;4(10):933-5. https://doi.org/10.1016/j.ijscr.2013.07.032.

32. Huang Y, Liu L, Li Q, Zhang S. Giant ganglioneuroma of thoracic spine: a case report and review of literature. J Korean Neurosurg Soc. 2017. https:// doi.org/10.3340/jkns.2015.0708.010.

33. Yorita $\mathrm{K}$, et al. Posterior mediastinal ganglioneuroma with peripheral replacement by white and brown adipocytes resulting in diagnostic fallacy from a false-positive 18F-2-fluoro-2-deoxyglucose-positron emission tomography finding: a case report. J. Med. Case Rep. 2014. https://doi.org/ 10.1186/1752-1947-8-345.
34. Taki K, et al. Giant liposarcoma of the posterior mediastinum and retroperitoneum. BMJ Case Rep. 2011. https://doi.org/10.1136/bcr.06.2011.4341.

35. Zsolt B, Ákos B. Surgical excision of a giant schwannoma located in the posterior mediastinum and partially in the retroperitoneum. Orv Hetil. 2019. https://doi.org/10.1556/650.2019.31495.

36. Galganski LA, Hirose S, Saadai P. Resection of a thoracoabdominal ganglioneuroma via a retroperitoneal minimally invasive approach. J Pediatr Surg Case Rep. 2019. https://doi.org/10.1016/j.epsc.2018.10.012.

37. Ma X, et al. Surgical removal of adult recurrent neuroblastoma located in the posterior mediastinum and retroperitoneum: a case report. Med (United States). 2018. https://doi.org/10.1097/MD.0000000000013642.

38. Shimogawara $T$, et al. Aortic sarcoma mimicking a mycotic aneurysm in the thoracoabdominal aorta. J Vasc Surg Cases Innov Tech. 2019. https://doi. org/10.1016/j.jvscit.2019.07.007.

39. Karangelis D, Nikolaidis N, Roubelakis A, Weeden DF. Giant thoracoabdominal ganglioneuroblastoma in a 17-year-old patient. Asian Cardiovasc Thorac Ann. 2014. https://doi.org/10.1177/0218492313490410.

40. Gow KW, Koontz CS, Dickson P, Bannister L, Shehata B. Retropleural teratoma presenting as an abdominal mass in a 9-month-old boy. J Pediatr Surg. 2010. https://doi.org/10.1016/j.jpedsurg.2010.07.014.

41. Nistor C, Ciuche A, Davidescu M, Horvat T, Tudose A. A giant thoracoabdominal tumor - hereditary multiple exostoses. Chir. 2009.

42. Luis AL, Martínez L, Hernández F, et al. Neuroblastomas congénitos [Congenital neuroblastomas]. Cir Pediatr. 2004;17(2):89-92.

43. Zambudio Carmona GA, Ruiz Jiménez Jl, Gutiérrez Canto MA, Tujillo Ascanio A, Vera M. Neuroblastoma en la infancia. Revisión clínica y de dos pautas de tratamiento [Neuroblastoma in childhood. Review of clinical aspects and of 2 forms of treatment]. Cir Pediatr. 1993;6(2):55-8.

44. Chang CY, Hsieh YL, Hung GY, Pan CC, Hwang B. Ganglioneuroma presenting as an asymptomatic huge posterior mediastinal and retroperitoneal tumor. J Chin Med Assoc. 2003;66(6):370-4.

45. Galganski LA, Hirose S, Saadai P. Resection of a thoracoabdominal ganglioneuroma via a retroperitoneal minimally invasive approach. J Pediatr Surg Case Rep. 2019;40:47-9.

\section{Publisher's Note}

Springer Nature remains neutral with regard to jurisdictional claims in published maps and institutional affiliations.

Ready to submit your research? Choose BMC and benefit from

- fast, convenient online submission

- thorough peer review by experienced researchers in your field

- rapid publication on acceptance

- support for research data, including large and complex data types

- gold Open Access which fosters wider collaboration and increased citations

- maximum visibility for your research: over $100 \mathrm{M}$ website views per year

At $\mathrm{BMC}$, research is always in progress.

Learn more biomedcentral.com/submissions 